\title{
Perceptions of Individual Behavior in Green Event-From the Theory of Planned Behavior Perspective
}

\author{
Jing Wang \\ Department of Event Economy and Management, College of Economy and Trade, Zhongkai University of Agriculture \\ and Engineering, Guangzhou, China \\ Email: amanda_wong@live.cn
}

How to cite this paper: Wang, J. (2017) Perceptions of Individual Behavior in Green Event-From the Theory of Planned Behavior Perspective. American Journal of Industrial and Business Management, 7, 973-988.

https://doi.org/10.4236/ajibm.2017.78070

Received: July 27, 2017

Accepted: August 14, 2017

Published: August 17, 2017

Copyright $\odot 2017$ by author and Scientific Research Publishing Inc. This work is licensed under the Creative Commons Attribution International License (CC BY 4.0).

http://creativecommons.org/licenses/by/4.0/

\begin{abstract}
Being an indispensable component of tourism industry, the event industry is growing rapidly over the past decades in terms of diversity, size, number and popularity. Meanwhile, the issue of greening industry is at the epicenter of international concern nowadays. Obviously, not merely event organizers need to adopt various green strategies to greening the events, but also every individual has the responsibility to perform eco-friendlier behaviors to make the event greener. Therefore, this paper begins by a background introduction of the urgent environmental problems nowadays, current greening development of event industry, and present relevant researches. Then the literature review of related concepts and an example are provided. In the following section, the Theory of Planned Behavior is utilized as a framework to analyze the significance of every individual's environmentally friendly behavior in the greening of events process. And then some implications are discussed. Finally, the paper concluded with the opinion that though the Theory of Planned Behavior is not comprehensive enough to change people's actual behavior, it should be considered when event organizers plan and operate the event, since the greening event needs support and help from every individual.
\end{abstract}

\section{Keywords}

Individual Behavior, Green Event, The Theory of Planned Behavior

\section{Introduction}

Dying trees, storms, species extinction, water shortage, resource scarcity, which are all the consequences of environmental problems that we can feel, see and 
hear every moment today. Care it or not, taking action immediately to protect the only one planet should not go away. More people today have become realized of the urgent necessity to protection and restoration of the eco-system, and have been aware of the impact of their daily behavior, which are related to the healthy development of environment to some extent.

Consistent with this fact, the green practices have taken off in many imaginable industries. Within the tourism industry, sustainable development and greening the industry has been put forward for some time. Increasing numbers of segments prefer to showing solicitude for the seriousness of environmental pollution, and using green strategies as a trump card for winning in the competitive market nowadays. As a cutting-edge segment of the whole tourism industry, event industry definitely plays a positive role on it. It provides vital social, cultural, educational and economic benefits, and potential increase in tourism industry for lots of international destination. But the unfortunate fact is that this industry may also exploit the environment by using excessive materials before, during and after the event. All these usages will leave a huge number of wastes that negatively impact the environment. Consequently, the event industry should rethink and recognize the environment issue in the planning and operating procedures nowadays. Meanwhile, altering the event operations to be green is becoming a necessity to improve competitiveness in the whole market and provide a healthy earth for the next generation.

This article, firstly presents the background introduction of current urgent environmental problems. Secondly, it reviews the literature on event industry, green event and the Theory of Planned Behavior (TPB), and takes the 2008 Beijing Olympic Games as an example of green event. Thirdly, the article utilizes TPB as a theoretical framework to illustrate how attitude, subjective norms and perceived control influence individual environmentally friendly behavior. And it concludes with some implications and measures on green practices to improve individual behavior in current green events.

\section{Literature Review}

\subsection{Event Industry}

Event industry is a component of the whole tourism industry. The nomenclature of events includes mega-events, special, major, social, community and hallmark events. Events can be categorized by their sector or size, for instance, the conferences, meeting and exhibition, entertainment and arts, sports events and so forth. Meanwhile, events can also be categorized by virtue of their scale, scope and size. Moreover, it can be defined as an organized occasion, such as a gala dinner, special events, expo and so forth [1]. An event is always composed of many different but interrelated functions, and this industry is closely linked to human race, including social and cultural values, the sense of belonging and identity [2]. It is evident that hosing an event will create many impacts, such as civic pride, community development, increased employment opportunities, ad- 
ditional trade and business development, earn money from event product extensions, raising awareness of environmental issues and so forth. Nevertheless, it also brings negative influences to human being, such as resident exodus, increased risk of security issues, traffic congestion, waste and pollution, disruption of lifestyle and so forth [3]. Therefore, there are many major developments toward the events industry becoming sustainable and green.

\subsection{Green Event}

The term of "green event" is quite a new word in the event industry, and there is no consensus of the word nowadays. It is seen as part of the sustainability development and integrate with broader component of social, cultural, economic and environmental roles, combined with the reduce energy consumption, reuse sources and recycle materials associated with tourism [4]. Meanwhile, it claimed that sustainable development represents the development is not only meets the needs of the current generation, but also satisfy the needs of next and future generations [5]. Therefore, greening event can be explained as a specific event that has some green strategies or applies sustainable policy into the planning and operation processes, it is not just incorporate environmental responsibility, but also social, cultural and economic concern [6]. Currently, two types of events govern the green event debate [7], which means the events that have a natural affinity for the environment, such as birding festival, and sports events, especially the major mega-events like the Football World Cup, these mega-events pose themselves numerous environmental problems like water accumulation, shortages in transportation capacities, resource consumption and so forth. The business events are rarely study in this area, in terms of its commercial rationale [8]. Then, the strategy of greening an event operation should take into account economic, social and environmental improvement at the same time. A number of studies have emphasized how event organizers should do in the practical operation procedures to achieve green event, such as change the backpacking [7], reduce, reuse, and recycle the sources [9]. Thus green event should provide every aspect of the event, from the event venue, modes of transportation, to the supply of materials and resources, provision of catering and so forth [10], and meanwhile, greening event needs a change in every individual's attitude and behavior, because of greening attitude can be contagious [11]. Fortunately, although some business events, in terms of their greening practices, are relatively rare in relevant researches, because of their strong commercial rationale makes them unlikely early apply greenness. Many other events, such as 2008 Beijing Olympic Games [12], Byron Bay International East Coast Blues and Roots Festival in North East New South Wales in Australia [7], being conscious of the urgent environmental pollution issues (e.g., water pollution, vehicle emissions release that contribute to climate change, energy wasting), already positioned themselves as eco-friendly and green event, and also adopted some green strategies to make the events greener, such as choose event centers with hotels or with perfect mass 
transit options or within walking distance, use recycled resources, cooperate with stakeholders who hold environmental protection awareness, use eco-sensitive delegate bags and giveaways and so forth [13].

\section{Green Event Example: The 2008 Beijing Olympic Games}

Take 2008 Beijing Olympic Games as an example. Before hosting the megaevent, Beijing was seen as a serious polluted city. During the Olympic Games, greening runs through all the event processes, through the design and construction of venues, the use of resources and energy, the recycle of garbage, the most important is the event implement some green practices in educating people the environmentally friendly awareness and behavior. Firstly, the official organizers of the 2008 Beijing Olympic Games announced the Olympic Games as a "Green Olympic" as well as "High-tech and People's Olympic", which is a broad hint for people to know the theme of the event, and probably will influence people's attitude and behavior to some extent. Secondly, the event organizers made an environmentally protection plan focus mainly on water pollution, noise pollution control, traffic congestion and so forth, hence, the residents in Beijing enjoyed a two months' blue sky. Then, the Beijing Municipal Government has called upon local citizens to take public transport more, especially use more bicycle and rickshaws which have built the city's historical brand and image for many years, instead of driving private cars when they watch matches and competitions at the Bird's Nest and the Water Cube during the Olympic, expecting to increase the environmentally friendly attitudes [14]. What is more, in consideration of the reality that for the majority of Chinese people, especially those not living in Beijing, the Olympic Games could only be watched as a television event, the government emphasis media release and presence as an important influential way to awaken people's environmentally protection awareness [11], Liu Xiang, who is the most famous Chinese Olympic superstar, was invited as spokesperson to publicize the environmentally friendly attitude. Hence, Beijing has seized this change to raise public environmental awareness [15]. Therefore, by implementing many green strategies, the Beijing Olympic Games not only host successfully in an eco-friendly climate, improve local people's environmentally friendly attitude to some extent, but also, by placing itself on the global stage, Beijing get an opportunity to build an new city image as environmentally friendly participators and advocators, which is opposed to the image of ecological degradation city before. Although the full impact of these greening practices remains to be examined, the efforts indicated that the greening strategies should be adopted as one of the basic objectives of an event.

\subsection{The Theory of Planned Behavior}

It claimed that the Theory of Planned Behavior is the extension of the Theory of Reasoned Action [16]. The Theory of Reasoned Action suggests that two components are needed to account for the interrelationship between attitudes and behaviors. The first one is, the attitude towards a certain behavior might not be 
turned into real action because of social pressure from people surrounding. Therefore, subjective norm should be taken into consideration. The second one is, attitude and subjective norm always affect a certain behavior by promoting the formation of an intention to perform. It means the theory of Reasoned Action regarded that behavioral intention is the most important predictor of a certain behavior, and it is determined by the attitude and subjective norm. However, it said that the Theory of Reasoned Action was created to predict the volitional behaviors, or behaviors over which the individual has a mass of control [17], many performance or behaviors require some skills, opportunities and resources to be acted. Therefore, an individual may not plan to perform a certain behavior unless that behavior is supposed as under personal control. Consequently, taking this issue into account, the concept of perceived behavioral control was added to the Theory of Reasoned Action, hence, the Theory of Planned Behavior was formed. The Theory of Planned Behavior indicates that perceived behavioral control is an additional predictor of intention alongside attitude and subjective norm. Consequently, while the Theory of Reasoned Action just mainly concentrated on volitional factors when illustrating people's behavioral intentions, the Theory of Planned Behavior examines the effect of personal attitude, social surrounding as well as other non-volitional factors on individual's behavioral intentions [18]. It claimed that the most important determinant of a person' behavior is his or her intentions to engage in the specific behavior, namely an individual's intention to perform a behavior is the central motivational factor to influence a behavior. This intention is supposed to be effected by three factors [19], namely attitude toward the behavior, subject norm, and perceived behavioral control. Intentions indicate what a person will do and how hard he is planning to do, in order to get the good outcomes. It represents an individual's motivation or decision to perform the certain behavior, and the decisions may have the potential to guide actual behavior [20]. Many Models of attitude-behavior relations, for example, the Theory of Reasoned Action, the model of interpersonal behavior, the prototype-willing modes and so forth, are all suggest intentions an important role in predicting a specific behavior [17]. Therefore, intention is regarded to capture some motivational factors that influence a certain behavior.

\subsubsection{Attitude}

Firstly, attitude towards a certain behavior represents the perceived results of that behavior, and an individual's evaluation of the consequence [21]. This attitude is influenced by behavioral belief, which is the subjective believe that the behavior will produce a specific result, and it can be seen as individual's evaluation of a given behavior. For instance, people may perceive participating a green event as experiencing an environmentally friendly venue, enjoying healthy and organic food, and being responsible to the society, thus, he may more likely to engage in this green event. In other words, people's positive attitude towards a behavior will strengthen their intention to perform that behavior [18]. The more 
pleasant and willing the attitude towards the particular behavior, the stronger will be the person's intention to perform it.

\subsubsection{Subjective Norm}

Secondly, the subjective norm is explained as the perceived social pressure to perform or not to perform the behavior [16]. It is determined by beliefs about the opinions of specific important others, it is influenced by normative belief, which is the perceived behavioral expectation from the past experience or other referent individuals. For instance, if an individual's relatives, close friends or colleagues think participating a green event is commendable, his perceived surrounding social pressure to attend the green event would strengthen. It means that subjective norm is the perceived view of points of other people who are significant to that individual and influence his or her decision-making process.

\subsubsection{Perceived Behavioral Control}

Thirdly, the perceived behavioral control is defined as the ease or difficulty of performing the certain behavior [18]. It is influenced by control belief, which is the perceived factor that may promote or impede the performance of a given behavior [21]. Meanwhile, it is conductive to consider the impact of perceived behavioral control under two situations [22], one is optimal condition (complete volitional control), and the other is suboptimal condition (problems of volitional control). It means in the situation of optimal condition, the relationship between intention and behavior should be optimal, and perceived behavioral control should pay any influence to this relationship. In contrast, when the behavior is under suboptimal condition, the perceived behavioral control should moderate the relationship between intention and behavior.

In all, the previous researchers illustrated that the Theory of Planned Behavior is a good conceptual grounds for suggesting that people's attitude, subjective and perceived behavioral control represent a potential influence on their behavioral intention, and it suggested that some events already adopted green strategies to make the events greener. However, only a few studies focus on the relationship between individual's environmentally friendly behavior and green events, and the importance of individual behavior during the greening of events. As a matter of fact, this article uses the Theory of Planned Behavior as a framework to discuss the importance of educating people to perform environmentally friendly behavior for supporting the greening of event, and provides some measures for green practices in current green events.

\section{The Relationship between TPB and Individual Environmentally Friendly Behavior}

The Theory of Planned Behavior has been applied to examine many areas. For instance, it is used to illustrate customers' decision process to pay conventionalhotel prices for a late-model of green hotel [23]. Meanwhile, the theory has been used successfully to explain various environmentally friendly behaviors, such as 
the recycling behavior, composting behavior [19] and so forth. It is believed that by purchasing eco-friendly products, recycling packaging and disposing of the non-biodegradable rubbish properly, every individual could contribute to the environmental protection. Many researchers used the theory for examining the relationship between environmental attitudes and environmentally friendly behaviors.

\subsection{Attitude and Environmentally Friendly Behavior}

Firstly, it said that environmentally friendly behavior might result from an intentional decision-making process that refers to certain attitude or goal-oriented decisions that leading environmental friendly behavior [24]. It means people's intention will be stronger if they think the behavior is a socialized goal and is performing by other people. According to a research, the more people were intentionally to improve the environmental issues, the more likely were they to use eco-friendly products [25]. Also, the study aimed at reviewing the relationship between people's intention to use the transferium and their attitudes, subjective norms, and perceived behavior control found that, a pleasant attitude, an active subjective norm, plus high perceived behavioral control will be connected with a stronger intention to use the transferium-an eco-friendly public transportation, which is in line with the Theory of Planned Behavior. Secondly, it claimed that attitude towards a certain environmental problem is the best predictor of intention and behavior toward such specific problem [26]. An individual is more likely to carry out environmentally friendly behavior if he is concerned about the environmental protection issues. Environmental concern is explained as a person's attitude about environmental issues related to his or her behaviors. It is seen as an attitude that shows the extent to which an individual is cared about the problems to the environment, the consequence of such environmental problems for the healthy development of the earth, and the immediate need for human being to take action protecting the environment for the next generation. Accordingly, as there is increasing agreement that environmental behavior is related to the environmental concern, it can be suggested that environmental concern will influence behavioral attitude, and the degree of this environmental concern will affect the environmentally friendly behavior. For instance, an individual who is cared more about environmental issues are more likely to reduce using private car in certain situation than those who does not have the environmental concern.

\subsection{Subjective Norms and Environmentally Friendly Behavior}

Subjective norms mean individuals' perceptions of agree or disagree from others for performing the behavior, for example, some people who are significant for a person think that he should participate a green event. It means family, neighbors, co-workers would influence an individual's decision and intention to perform environmentally friendly behavior. A study showed that people would 
appreciate the eco-friendly behavior more if their surrounding people also do so [27]. From the study, we can see that group identification and norms will affect behavioral decision, and the behavior of other people will play as a guidance for proper behavior, especially when that behavior is significant to the self-concept. It is likely that for an individual, the environmentally friendly behavior perform by other people will make that behavior as a desirable behavior to engage in. Then, as the subjective norm is also the perceived behavioral expectation from the past experience, it showed that the future environmental friendly behavior will be affected by past eco-friendly behavior to some extent. For instance, if a child was used to perform some pro-environmental behaviors from his childhood, it is more likely for the child to perform more environmentally friendly behavior in his adulthood. Nevertheless, there is also argued that although the subjective norm is seen as the extent of pressure perceived from other people to perform a behavior, and people are more likely to participant in behavior that is relate to an approval climate [26], such pressures is probably potential and may not be perceived for behaviors that do not affect others around, or for behaviors that are indirectly related to destructive results. The subjective norm within the Theory of Planned Behavior is regarded as the weakest component by some studies. However, a study found evidence to claim that some actions and behaviors are driven mainly by subjective norms rather than attitudes or perceived behavior control [28].

\subsection{Perceived Control and Environmentally Friendly Behavior}

According to some models, intentions sometimes can only be expected to find performance on behavior if an individual possess actual perceived control over the behavior, it is more likely for a person to perform the specific behavior when perceptions of perceived control were high [17]. It therefore, argued that perceived behavior control is an important predictor of intentions for a green consumer to buy green products. Meanwhile, some researchers have examined that individual's intention is affected by his or her confidence in his or her ability to accomplish that behavior to some extent [29]. It means an individual's behavioral intention will be lower if he or her just has little control over performing a specific behavior due to lacking of some resource, such as time or money, regardless of the fact that he or her may have the positive attitude or subjective norm about the intended behavior. Hence, perceived behavioral control is also regarded as making a direct predictive influence on people's behavior in situation when a person's opinions of control equal the amount of accrual control that he or she is has the ability to practice.

\subsection{Other Variables and Environmentally Friendly Behavior}

However, although many findings from the past and present reviews confirmed that the predictive impacts of attitude, subjective norm, and perceived behavioral control would vary across the implementation of a behavior, and certain en- 
vironmentally friendly behavior related to the specific eco-friendly attitude, subjective norms and perceived behavior control, some other researchers also argued that the Theory of Planned Behavior is not enough to explain individual's behavior. A study aimed at examining the relationship between attitudes and behavior suggested that attitudes probably do not powerful enough to predict a behavior, because of the completion of an intention into actual behavior is sometimes determined by personal factors, environmental barriers and so forth [22]. As a consequence, it has been argued that there is no simple attitude-behavior relationship, and it is necessary to take into many other variables and components for the sake of predict behavior accurately. The study also suggested that although a great deal of literature indicated that behavior is largely determined by intentions to perform then, some other variable also should be considered into the analysis of the performance of a behavior, for instance, dual-process decision-making, habit, self-efficacy and so forth.

\subsubsection{The Dual-Process of Decision-Making Process}

Firstly, a study showed that not all of the behaviors are target-oriented or deliberative, an individual is likely to participate in some behaviors which are not desirable, the variance between attitude and actual behavior is probably caused by some intentional decisions as explained by the Theory of Planned Behavior, but also by unintentional decision [24]. A previous research suggested that unintentional decision-making, which as relative to situational factors, also will predict behavior coupled with intentional decisions-making [30]. And it suggested that the lack of accordance between environmentally friendly attitude and behavior is probably caused by situational factors relating to the acceptance of eco-friendly behavior, which means individual's environmentally friendly behavior may cause by a dual-process, including an intentional process that contains target-oriented decisions that lead environmentally friendly behavior, and a reactive process that contains the unplanned decisions to receive environmental friendly behaviors [31]. Firstly, in the intentional process, the target-oriented based upon behavioral intention, subjective norm and an attitudinal factor, and the behavioral intention for environmentally friendly behavior will determine the behavior for such process. This behavior intention derived from two terms, namely environmental concern and the subjective norm. An individual's intention to perform the environmentally friendly behavior would be stronger if they are more cared about the environmental issues and if they perceived the subjective norm because the behavior is considered to be a socialized goal. Secondly, in the reactive process, it supposes that the unplanned behavior based upon the behavioral willingness, descriptive norm and prototype image, and an individual's prototype image is more active if he or she is subject to more circumstances in favor of socially undesirable behavior. For example, the extent of environmental concern and the subjective norm will determine a person's behavioral intention for perform eco-friendly behavior, and this behavioral intention will affect his or her actual behavior. However, the behavior willingness will inhibit a 
person's recycling behavior to some extent, and this reactive process is one of the reasons that lead to the inconsistency between environmentally friendly attitude and behavior. Therefore, people's environmentally friendly behavior is probably facilitated or restrained according to whether the effect of an intentional decision to support this environmentally friendly is stronger, or else, whether the influence of a reactive decision to take in environmentally friendly behavior wins. And in order to perform the eco-friendly behaviors successfully, the intentional decision for environmentally friendly behavior need to restrain the influence of reactive decision favoring environmentally unfriendly behavior. Consequently, the relationship between attitude and behavior is not only attributed to intentional decision, but also caused by unintentional decision, the performance of environmentally friendly behavior involves dual-process, namely intentional decision- making process and reactive decision-making process.

\subsubsection{Habit}

Then, it suggested that habit can play a significant role in intentional processes as well [32]. More particularly, it argued that when a person is in the habit of performing a behavior, he can intend to do that habit in the future without involving too much subjective norm or putting much effort into the formation of the intention. Hence, there is no need to expect attitudes, subjective norm and perceived behavioral control to correlate with such intentions. And only when an individual is not in the habit of performing the specific behavior before is there reason to commit other components to the decision.

\subsubsection{Self-Efficacy}

Moreover, it is said the self-efficacy, rather than perceived behavioral control, has an important and direct influence on behavior. Some even suggest using the self-efficacy to replace the perceived behavioral control in the prediction of intention and behavior [22]. It said self-efficacy is regarded as an estimate of one's capability to perform a specific level of action. They argued that self-efficacy is more involved with internal control factors, while perceived behavioral control only reflects the general and external factors. For instance, for environmentally friendly behavior, perceived behavioral control only has an effect on discussing the use of green product at a venue, whereas self-efficacy has a strong effect on discussing the intention to use such green products. It means perceived behavioral control only predict exercise behavior, self-efficacy predicts the intentions. Furthermore, some authors claimed that perceived difficulty is more similar to Ajzen's original conception of planned behavior [33]. According to their studies, perceived difficulty would predict behavior intention independently, but perceived behavioral control cannot. Therefore, they regard the self-efficacy is a useful predictive component of intention and behavior.

\subsubsection{Personal Norms}

Furthermore, personal norms will also influence people's behavior expect atti- 
tude, subjective norms and perceived behavior control. It is said that the concept of personal norm should contribute to the explanation of the intention to perform a certain environmentally relevant behavior. For instance, an individual's attitude of using the unbleached paper was desirable for a person before, but will much weaker when the personal norm was added. From a study aimed at examining the decision of shoppers and employees to use transferium instead of drive private car in America, it found that both of shoppers and employees have the attitude and concern of environmental protection, but shoppers have a relative stronger intention to use the transferium [25]. Because of the shoppers are facing more difficulties finding parking spaces, paying more fees for parking, while employees always no need to pay for parking and seldom encounter parking problems. Therefore, the research indicates that for the sake of promoting attitudes of performing some environmentally friendly behavior, it is important to stress the direct individual benefits of performing that behavior.

\subsubsection{The Inconsistency between Attitude and Behavior}

The last but not the least, there is a prevailing opinion that although people who strongly favor environmental protection are more likely to perform environmental friendly behavior, environmental attitudes are not always correlated with behavior successfully [34], and attitude change does not always lead to behavioral. For instance, a study showed that trying to change environmental attitudes always has little effect on behavior. In 1977, a three-hour workshop conducted in Virginia in order to educate people about energy conservation in the home. The workshop was effective in changing participant's attitudes and beliefs beforeand-after the program. After the workshop, participants expressed increased concern about the energy crises, increased awareness that even simple changes in their own home can contribute huge energy saving, and stronger beliefs that they could do something about the environmental issue. But these attitudes and beliefs changing did not translate into behavioral change. Follow-up visits to all participants' homes after the workshop indicated that only one of the forty participants had lowered a water heater thermostat, and only eight of the participants had installed low-flow showerheads. Many reasons could explain why people did not take action reflect their attitude. One possible explanation of this inconsistency is the gap between attitudes and behaviors. For instance, a person may know he should perform environmentally friendly behavior, but he may not have necessary time or money, may not want to change a heating system in his home that is functioning adequately, may think he does not have the right to use less water in an event venue. Also, lacking of accurate information can be another barrier to perform behavior follow attitude changed, because the connection between behavior and its environmental effect can be impossible to discern from personal experience, and it is not always clear to an individual how to perform efficiently on his attitudes, many people do not know which behavior is environmentally friendly or effective eco-friendly. 


\section{Implications}

Given above studies, although the Theory of Planned Behavior may not predict the environmentally friendly behavior roundly and educate every individual to perform eco-friendly behavior, it indeed indicates that the more likely individuals regard their performance can contribute to greening the environment, the more likely they are to perform environmentally friendly behaviors. It shows that the event managers and organizers, relevant scholars and environmentalist should think highly of the greening of event industry, and the event industry should find some way to increase every individual's positive attitude in order to enhance their intention to perform eco-friendly behavior, and also possibly conductive to building their positive attitudes about environmentally friendly behaviors for the development of greening event in the long-term. By doing this, individual would obtain beliefs that they could be more helpful and socially response for the greening of event industry and protecting our environment [35].

For instance, future development of event industry could focus more on the field of "environmentally themed events", and how successful the green strategies have been. The role green events could be regarded as a case of socially responsible mutual behavior, which could in turn build some parts of green events as a new type of "responsible tourism". Meanwhile, the term of "green event" can be conceptualized as an event that take a sustainable principle or incorporates green strategies into its planning, management and operation, and the sustainability can be explained as encompassing not merely environmental concern, but also social, cultural and economic sustainable development, such as the Byron Bay International East Coast Blues and Roots Festival in Australia, which adopt green strategies not only aimed at hosing an eco-friendly event with zero waste, but also focus on hosting a culturally relevant festival with respect to local community.

Secondly, it claimed that simply telling people to change the attitude is not enough to make a behavior change. More efforts should adopt, such as deliver the environmental protection information that caught people's attention and made the information credible rather than simply providing people with straight forward information via events. It is effective to increase environmentally friendly behavior by getting people to make a public commitment to take an action. A public commitment seems to strengthen individual's personal commitment to the behavior. When people's attitudes and the expectations of others, approve protecting the environment, it helps to remind people of that issue, which is similar to the attitude of the Theory of Planned Behavior.

Thirdly, using social networks to diffuse environmentally friendly information, as it is easy to see that information coming from individuals someone know and trusts is particularly effective, and it will increase involvement as well, since whatever someone does with information from a trusted friend or neighbor is likely to affect the future behavior related to the information, which is similar to the subjective norm of the Theory of Planned Behavior. 
Moreover, for people whom participants the event, some environmental slogans and reminders should be seen everywhere in the event venue, such as "keep our home beautiful", "every litter bit helps", and the like. These messages are designed neither to change attitudes nor to give information, but simply to remind participants to do things that they are already knowledgeable to do. Timely and specific reminder can be effective, and also help to overcome internal action barriers such as forgetting or laziness, which is related to the perceived behavior control of the Theory of Planned Behavior.

The last but not least, there are lots of green behaviors we can perform, for instance, when an individual chooses to go the event venue by private car or taxi instead of taking public buses or trains, he or she can enjoy the comfort for a moment. However, in the long term, this behavior might endanger the environment and event development, thus, choosing the mass transit is a simple but significant personal behavior every individual can take to reduce global warming. We should individually take responsibility for our own actions, including our contribution to the state of the planet.

\section{Conclusions}

Taking the urgent environment problem, increasing environment protection awareness and sustainable development realization into consideration, every relative authority should bring new regulations, guidelines and principles into the event organization. For the event industry, as an indispensable part of tourism industry, studies have only recently researched the environmental aspect of events in earnest, and put the term of "green event" forward in this climate. To date, little has been specifically published about green event, and few investigations focus on how to host green events and how to encourage its participants to perform more environmentally friendly behavior. Obviously, not merely event organizers need to adopt more green strategies, but also every individual has the responsibility to perform eco-friendlier behavior.

Therefore, this paper utilizes the Theory of Planned Behavior as a framework to analyze the significance of every individual's environmentally friendly behavior in the greening of events process. The Theory of Planned Behavior is an extension of the Theory of Reason Action. It adds a measure of perceived behavioral control, with attitudes and subjective norm, as a predictor of intentions. An attitude is the target individual's opinion about whether a specific behavior is positive or negative, and the subjective norm is the target individual's opinion about what others who are important to him or her think he or she should do, and the perceived behavior control is defined as the ease or difficulty level of performing a certain behavior. In so doing, insights on the significance of individual environmentally friendly behavior for improving the greening of event industry were gained. As discussed earlier, although the theory is not comprehensive to change every individual's actual behavior, as individual differences in realization are likely to result in individual differences in behavior, event orga- 
nizers should adopt some green practicing in event operation, and by implementing such green strategies in the planning and organization processes. Upon applying green management, the event organizers should also focus more on how to improve every participant's environmentally friendly concern, and change their attitude in order to make sure a more environmentally friendly behavior in the future. By increasing the strategy of greening event implementation, one would positively change the attitude of environmentally friendly behavior, which would affect the environmentally friendly behavior awareness of local population, employees, partners, participants and community people as well. Since the greening event not only fits into the increasing awareness of environmental protection, and benefits the development of event industry, but also, it will benefit everyone currently and make a more beautiful picture for the future generations.

The study presented here only offers a new research perspective of event greening process, and such initial exploration can be used as a reference for other relevant researches. There is a wide range of topics that deserve further scholarly scrutiny, such as individual satisfaction with current green event, individual expectation of green materials and so forth. To study this phenomenon in depth and from different perspectives, such as waste disposal system, low-carbon lifestyle, inputs and outputs, will provide a wealth of insights. Besides its scholarly relevance, this paper also provides several relevant green strategies for improving the current situation, and it can serve as a toll to foster the discussion on event industry greening management.

Achieving the greening of event and implying greenness attitude to behavior is not a simply task. In future research, it would be interesting to study some aspects of behavior of participants, in order to know their participant motivations, their decision-making processes with respect to attending events, their expectation of green contents of events and so forth, in order to provide more details about individual's behavior and what event could do in the future for greening practices. The researches on green event should not merely focus on success factors, but also the examples of failure, to provide more guidance for the sake of building a more perfect picture of the greening of event.

\section{References}

[1] Getz, D. (2008) Event Tourism: Definition, Evolution, and Research. Tourism Management, 29, 403-428. https://doi.org/10.1016/j.tourman.2007.07.017

[2] Janiskee, R. (2006) Event Management \& Event Tourism. Annals of Tourism Research, 33, 872-873. https://doi.org/10.1016/j.annals.2006.03.005

[3] Lesjo, J.H. (2000) Lillehammer 1994: Planning, Figurations and the 'Green’ Winter Games. International Review for the Sociology of Sport, 35, 282-293. https://doi.org/10.1177/101269000035003003

[4] Getz, D. (2009) Policy for Sustainable and Responsible Festivals and Events: Institutionalization of a New Paradigm. Journal of Policy Research in Tourism, Leisure \& Events, 1, 61-78. https://doi.org/10.1080/19407960802703524 
[5] Jenkinsa, C.L. (2010) Tourism Development and the Environment: Beyond Sustainability? Journal of Policy Research in Tourism, Leisure and Events, 2, 195-196. https://doi.org/10.1080/19407963.2010.482285

[6] Laing, J. and Frost, W. (2010) How Green Was My Festival: Exploring Challenges and Opportunities Associated with Staging Green Events. International Journal of Hospitality Management, 29, 261-267. https://doi.org/10.1016/j.ijhm.2009.10.009

[7] Merrilees, B. and Marles, K. (2011) Green Business Events: Profiling through a Case Study. Event Management, 15, 361-372. https://doi.org/10.3727/152599511X13175676722609

[8] Mair, J. and Jago, L. (2010) The Development of a Conceptual Model of Greening in the Business Events Tourism Sector. Journal of Sustainable Tourism, 18, 77-94. https://doi.org/10.1080/09669580903291007

[9] Murphy, L.A. (2010) The Greening of Venues. Expo Magazine, 22, 30-35.

[10] Sander, G. and Lugaric, R. (2010) Green Strategy of Business Tourism. Tourism \& Hospitality Management, 337-349.

[11] Beyer, S. (2006) The Green Olympic Movement: Beijing 2008. Chinese Journal of International Law, 5, 423-440. https://doi.org/10.1093/chinesejil/jml018

[12] Ernst, M., Sperlich, A., Zheng, X., Gan, Y., Hu, J., Zhao, X. and Wang, J. (2007) An Integrated Wastewater Treatment and Reuse Concept for the Olympic Park 2008, Beijing. Wastewater Reclamation and Reuse for Sustainability, 202, 293-301. https://doi.org/10.1016/j.desal.2005.12.067

[13] Martins, C. (2006) Why Green Events Matter. Conference \& Exhibition Fact Finder, $22,28$.

[14] Jiang, K., Zhu, S. and Shrestha, R.M. (2007) Analysis of Policy Options for Promotion of Clean and Energy Efficient Technologies in the Transport Sector in Beijing. International Journal of Environment \& Pollution, 30, 59-68. https://doi.org/10.1504/IJEP.2007.014502

[15] Cheung, K.Y. (2010) Economic Analysis of the Beijing Green Olympics: Implications on Environmental Protection in China. International Journal of Economics and Finance, 2, 104-113. https://doi.org/10.5539/ijef.v2n3p104

[16] Ajzen, I. (1991) The Theory of Planned Behavior. Organizational Behavior and Human Decision Processes, 50, 179-211. https://doi.org/10.1016/0749-5978(91)90020-T

[17] Webb, T.L. and Sheeran, P. (2006) Does Changing Behavioral Intentions Engender Behavior Change? A Meta-Analysis of the Experimental Evidence. Psychological Bulletin, 132, 249-268. https://doi.org/10.1037/0033-2909.132.2.249

[18] Han, L.-T. and Sheu, C. (2010) Application of the Theory of Planned Behavior to Green Hotel Choice: Testing the Effect of Environmental Friendly Activities. Tourism Management, 31, 325-334. https://doi.org/10.1016/j.tourman.2009.03.013

[19] Fielding, K.S., McDonald, R. and Louis, W.R. (2008) Theory of Planned Behaviour, Identity and Intentions to Engage in Environmental Activism. Journal of Environmental Psychology, 28, 318-326. https://doi.org/10.1016/j.jenvp.2008.03.003

[20] Hirose, Y. and Ohtomo, S. (2007) The Dual-Process of Reactive and Intentional Decision-Making Involved in Eco-Friendly Behavior. Journal of Environmental Psychology, 27, 117-125. https://doi.org/10.1016/j.jenvp.2007.01.005

[21] Ajzen, I. (2001) Nature and Operation of Attitude. Annual Review of Psychology, 52, 27-58. https://doi.org/10.1146/annurev.psych.52.1.27

[22] Conner, M. and Armitage, C.J. (2001) Efficacy of the Theory of Planned Behavior: 
A Meta-Analytic Review. The British Journal of Social Psychology, 40, 471. https://doi.org/10.1348/014466601164939

[23] Kim, Y. and Han, H. (2010) Intention to Pay Conventional-Hotel Prices at a Green Hotel-A Modification of the Theory of Planned Behavior. Journal of Sustainable Tourism, 18, 997-1014. https://doi.org/10.1080/09669582.2010.490300

[24] Shoji, O. and Yukio, H. (2007) The Dual-Process of Reactive and Intentional Decision-Making Involved in Eco-Friendly Behavior. Journal of Environmental Psychology, 27, 117-125. https://doi.org/10.1016/j.jenvp.2007.01.005

[25] De Groot, J. and Steg, L. (2007) General Beliefs and the Theory of Planned Behavior: The Role of Environmental Concerns in the TPB. Journal of Applied Social Psychology, 37, 1817-1836. https://doi.org/10.1111/j.1559-1816.2007.00239.x

[26] Abdul-Muhmin, A.G. (2007) Explaining Consumers' Willingness to Be Environmentally Friendly. International Journal of Consumer Studies, 31, 237-247. https://doi.org/10.1111/j.1470-6431.2006.00528.x

[27] Dolnicar, S. and Grün, B. (2009) Environmentally Friendly Behavior: Can Heterogeneity among Individuals and Contexts Environments Be Harvested for Improved Sustainable Management? Environment \& Behavior, 41, 693-714.

https://doi.org/10.1177/0013916508319448

[28] Trafimow, D. and Finlay, K.A. (1996) The Importance of Subjective Norms for a Minority of People: Between Subjects and Within-Subjects Analyses. Personality and Social Psychology Bulletin, 22, 820-828. https://doi.org/10.1177/0146167296228005

[29] Baker, E.W., Al-Gahtani, S.S. and Hubona, G.S. (2007) The Effects of Gender and Age on New Technology Implementation in a Developing Country: Testing the Theory of Planned Behavior (TPB). Information Technology \& People, 20, 352-375. https://doi.org/10.1108/09593840710839798

[30] Gibbons, F.X., Gerrard, M., VandeLune, L.S., Wills, T.A., Brody, G. and Conger, R.D. (2004) Context and Cognitions: Environmental Risk, Social Influence, and Adolescent Substance Use. Personality and Social Psychology Bulletin, 30, 10481061. https://doi.org/10.1177/0146167204264788

[31] Ohtomo (2004) Dual Decision Making Process of Environment Risk Behavior and the Influence of Prototype Perception of the Environmentally Non-Conscious Person. Environmental Education, 13, 25-34.

[32] Trafimow, D. and Duran, A. (1998) Some Tests of the Distinction between Attitude and Perceived Behavioral Control. British Journal of Social Psychology, 37, 1-14. https://doi.org/10.1111/j.2044-8309.1998.tb01154.x

[33] Sparks, P., Guthrie, C.A. and Shepherd, R. (1997) The Dimensional Structure of the 'Perceived Behavioral Control' Construct. Journal of Applied Psychology, 27, 418438.

[34] Tilley, F. (1999) The Gap between the Environmental Attitudes and the Environmental Behavior of Small Firms. Business Strategy and the Environment, 8, 238248.

https://doi.org/10.1002/(SICI)1099-0836(199907/08)8:4<238::AID-BSE197>3.0.CO; $\underline{2-\mathrm{M}}$

[35] Cunningham, G.B. and Kwon, H. (2003) The Theory of Planned Behaviour and Intentions to Attend a Sport Event. Sport Management Review, 6, 127-145. https://doi.org/10.1016/S1441-3523(03)70056-4 
Submit or recommend next manuscript to SCIRP and we will provide best service for you:

Accepting pre-submission inquiries through Email, Facebook, LinkedIn, Twitter, etc. A wide selection of journals (inclusive of 9 subjects, more than 200 journals)

Providing 24-hour high-quality service

User-friendly online submission system

Fair and swift peer-review system

Efficient typesetting and proofreading procedure

Display of the result of downloads and visits, as well as the number of cited articles Maximum dissemination of your research work

Submit your manuscript at: http://papersubmission.scirp.org/

Or contact ajibm@scirp.org 